\title{
American Society for Stereotactic and Functional Neurosurgery Bestows Distinguished Service Award on Dr. med. h.c. mult. Thomas Karger and Prof. Dr. Phil Gildenberg
}

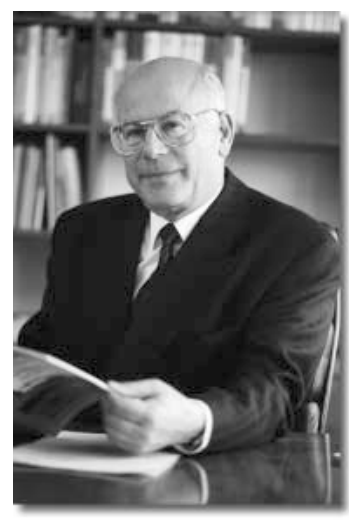

Dr. med. h.c. mult. Thomas Karger

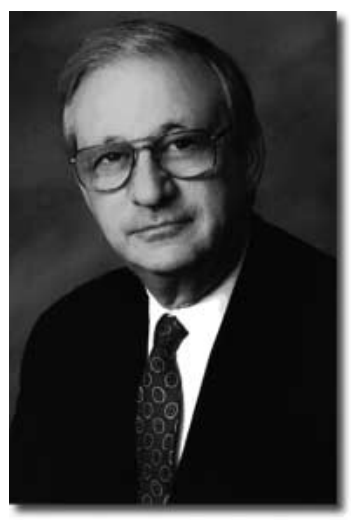

Prof. Dr. Phil Gildenberg
In recognition of their outstanding and ongoing contributions to the field of stereotactic and functional neurosurgery, Dr. Thomas Karger and Prof. Phil Gildenberg together received the Distinguished Service Award of the American Society for Stereotactic and Functional Neurosurgery (ASSFN) at its Quadrennial Meeting in New York, on May 19th, 2003.

In times when stereotaxy was less popular than it is today, Prof. Gildenberg, as Editor-in-Chief of the journal Stereotactic and Functional Neurosurgery, and Dr. Thomas Karger, as its publisher, worked together to support endeavours in this field by the publication of high-quality research. As official organ of the ASSFN, and through the close collaboration between society, Editor-in-Chief and publisher, the journal has contributed to no little extent to the prominent place this subspecialty of neurosurgery enjoys today.

Dr. Thomas Karger was born in 1930 and assumed control of the family-run publishing enterprise S. Karger AG on the early death of his father in 1959. In over 40 years of leadership, he succeeded in transforming Karger into a biomedical publisher of international renown and worldwide representation. Since 1999 his son, Steven Karger, has been the company's CEO, and Dr. Thomas Karger continues to serve as President of the Board of Directors. Today, Karger publishes over 75 journals, one of which is Stereotactic and Functional Neurosurgery, as well as serial and non-serial books.

Founded in 1938 by Dr. Ernest Spiegel, who was the initiator of stereotactic surgery, Stereotactic and Functional Neurosurgery provides a single source for the reader to keep abreast of developments in this rapidly advancing subspecialty within neurosurgery. Technological advances in computer and graphic science are being applied to clinical problems with ever-increasing rapidity in stereotaxy more than any other field, providing opportunities for new approaches to surgical and radiotherapeutic management of diseases of the brain, spinal cord and spine. Prof. Gildenberg, who was also awarded the Spiegel-Wycis Medal by the World Society for Stereotactic and Functional Neurosurgery in 1997, was taught by Dr. Spiegel, and served as the journal's Editor-in-Chief from 1975 to 2001. He continues to give the journal the benefit of his many years of experience as Associate Editor.

For further information on the journal please visit the website www.karger.com/sfn

\section{KARGER}

Fax +41613061234 E-Mail karger@karger.ch www.karger.com
(C) 2003 S. Karger AG, Basel 